\title{
When Fairness is Especially Important: Reactions to Being Inequitably Paid in Communal Relationships
}

\author{
Susanne L. Peters $\cdot$ Kees van den Bos
}

Published online: 22 February 2008

(C) Springer Science+Business Media, LLC 2008

\begin{abstract}
This article focuses on when justice is especially important to people and, in doing so, explores the social conditions under which the importance of justice may change in social interactions. More specifically, the authors examine how different types of relationships affect evaluations of equitable and inequitable situations. It is argued that when people are confronted with friends as interaction partners, as opposed to unknown others, they are motivated to attend to the needs of their friends (Clark \& Mills, Journal of Personality and Social Psychology, 37, 12-24, 1979) and, therefore, they are not only concerned with their own outcomes, but also with their friends' outcomes. As predicted on the basis of this line of reasoning, two experiments demonstrate that when people's interaction partners are friends, people are indeed more satisfied with being underpaid and less satisfied with being overpaid compared to when their interaction partners are unknown others. In the discussion, it is argued that these findings suggest that justice is especially important to people when they are in communal relationships.
\end{abstract}

Keywords Fairness · Equity · Inequity - Communal relationships ·

Friends · Unknown others

The concern for justice is a universal human characteristic, as people are intrinsically motivated to behave fairly and believe that justice exists in the world (e.g., Lerner, 1980, 1981). This said, however, there are important situational variations in the importance and meaning of justice across social situations (see,

S. L. Peters

WODC, Ministry of Justice, The Hague, The Netherlands

K. van den Bos $(\bowtie)$

Department of Social and Organizational Psychology, Utrecht University, Heidelberglaan 1, Utrecht 3584 CS, The Netherlands

e-mail: k.vandenbos@uu.nl 
e.g., Tyler \& Smith, 1998). In the present article, we would like to focus on the question of when justice is important to people. Here, we will explore the social conditions under which the importance of justice may change in social interactions. More specifically, we will examine how different types of relationships affect people's reactions to equitable and inequitable situations. That is, we will argue that having a communal relationship with interaction partners, as opposed to having an exchange relationship, plays an important role in evaluating outcome distributions and, more specifically, inequitable outcome distributions. With the current research, we attempt to integrate the literature on equity theory with the literature on communal and exchange relationships.

\section{Equity Theory}

Equity theory has examined what people think is equitable and fair and how people react to equitable and inequitable outcomes (see, e.g., Adams, 1965; Walster, Berscheid, \& Walster, 1973; Walster, Walster, \& Berscheid, 1978). The basic principle underlying equity theory is that there should be a balance between inputs and outcomes of two persons. Equity theory distinguishes between equitable and inequitable outcome distributions. Equity exists for people whenever they perceive that the ratio of their outcomes to inputs is equal to the input-outcome ratio of a comparable other person. In order to illustrate this principle, it is generally perceived as equitable and fair if two people who have worked equally hard receive an equal amount of money for their work. Inequity, on the other hand, exists for people whenever they perceive that the ratio of their outcomes to inputs is unequal to the ratio of another person's outcomes to inputs. Inequity results for people not only when they are relatively underbenefitted, but also when they are relatively overbenefitted. Both inequitable outcome distributions (i.e., being underpaid and being overpaid) are studied in this article, together with equitable outcome distributions.

On the basis of equity theory (e.g., Adams, 1965; Austin, McGinn, \& Susmilch, 1980; Austin \& Walster, 1974; Buunk \& Van Yperen, 1989; Van den Bos, Lind, Vermunt, \& Wilke, 1997), it can be argued that, when forming judgments of outcome satisfaction, individuals who are faced with inequity will feel distress and will be less satisfied than individuals who are confronted with equity. As noted by Adams (1965): "There can be little doubt that inequity results in dissatisfaction" (p. 283). Thus, receiving equitable outcomes results in satisfaction, suggesting that fairness concerns have a big impact on outcome evaluations. Related findings show that people are only moderately satisfied with overpayment-more so than with underpayment and, interestingly, less so than with equitable payment. These findings are generally viewed to suggest that fairness concerns have a big impact on outcome evaluations (Montada, 2002; Van den Bos, Peters, Bobocel, \& Ybema, 2006).

At the same time, however, Walster and colleagues (1973) have argued that equity theory rests on the assumption that people are selfish. According to this line of reasoning, people want to live a nice life, and for these and other hedonistic 
reasons pursue their self-interest (see, e.g., Hobbes, 1651/1904). There are numerous situations that motivate people to pursue their self-interest (for overviews, see, e.g., Komorita \& Chertkoff, 1973; Schwartz, 1986). In other words, it is generally assumed that self-interest is also important to people. Thus, support has been found both for the notion that fairness is important to people (Montada, 2002; Van den Bos et al., 2006) and for the idea that people pursue their self-interest (see Komorita \& Chertkoff, 1973; Schwartz, 1986). On the basis of research on judgment and choice (e.g., Boles \& Messick, 1995; Loewenstein, Thompson, \& Bazerman, 1989; Messick \& Sentis, 1985), we will argue here that both motives (fairness and self-interest) might affect people's reactions to the overpayment and underpayment outcome distributions outlined earlier.

In the present article, we are concerned with the social conditions that determine when fairness is important to people. For this purpose, we focus on the effects that different types of social interactions may have on how people react to equitable and inequitable outcome distributions. It is important to note here that, in equity experiments, participants usually interact with other participants, whom they have not met before. Interestingly, however, it is much more common for people in their daily lives to interact with people they know than to interact with unknown others. More specifically, we think for reasons to be specified below, that it would be especially interesting to see what happens when people would be evaluating outcome distributions with regard to others who are close to them instead of unknown others. Surprisingly, this, to our knowledge, has not been investigated before. We think that the type of relationship people have with their interaction partner should have a big influence on how they react to inequitable outcomes, and, therefore, building on the literature on close relationships, we will focus on people's reactions toward equitable and inequitable outcome distributions in both communal and in exchange relationships. Apart from this, within a broader scope, we also relate this research to literature concerning categorization and intergroup relations about categorization effects, in-group versus out-group concepts, and biases in favor of the in-group (Brewer, 1979; Tajfel \& Turner, 1979). We will elaborate upon this in the discussion of the present article.

\section{Communal and Exchange Relationships}

Clark and Mills (1979, 1993; Mills \& Clark, 1982) have made an important distinction between different types of relationships people have with interaction partners. In most of their work, these authors make a distinction between communal relationships and exchange relationships. In communal relationships people feel a mutual responsibility for one another's needs. Communal relationships are often exemplified by relationships among friends, romantic partners, and family members. In exchange relationships, on the other hand, people are not motivated to act for the needs of the other. Exchange relationships are often typified by relationships among strangers, acquaintances, and business associates. The distinction between communal and exchange relationships is based upon the implicit rules governing the distributions of benefits in relationships (Clark \& Mills, 1979, 1993; Mills \& Clark, 
1982). This focus on distributions in relationships makes it even more surprising that the link between, on the one hand, communal and exchange relationships, and, on the other hand, how people react to outcome distributions has not been studied before. Here, we integrate the literature on equity evaluations with the literature on communal and exchange relationships.

The most common manipulation of communal versus exchange relationships is having people interact with friends versus unknown others (see, e.g., Clark \& Mills, 1979, 1993; Clark, Mills, \& Corcoran, 1989; Mills \& Clark, 1982). In the present article, therefore, we extend this research tradition by comparing how satisfied people are with equitable and inequitable outcome distributions when they interact with friends versus unknown others. One of the reasons why we think it is interesting to study the impact of communal and exchange relationships on evaluations of outcome satisfaction is that this can be related to the literature regarding the closeness of an interaction partner. For example, Kelley and Thibaut (1978) have shown that members of a close relationship each have a pattern of perceived interdependence of outcomes in which partners and joint benefits are expected in the long run to benefit the self. Similarly, Aron and Aron (1986; Aron, Aron, Tudor, \& Nelson, 1991) have suggested that in close relationships the other is included in the self. In other words, in close relationships the other in a way merges with the self and the two persons can be considered to be part of a team. This is illustrated, for example, by the fact that in close relationships people act as if some or all aspects of the partner are partially the person's own (Aron et al., 1991), and that people in close relationships experience a sense of "we-ness" (see, e.g., Hatfield, 1982; McDonald, 1981).

\section{Communal and Exchange Relationships in Inequitable Situations}

Research that has investigated the effects of interacting with friends versus unknown others has shown that people who interact with friends, compared to those who interact with unknown others, attend more to the other's needs (Clark et al., 1989), help the other more (Clark, Ouellette, Powell, \& Milberg, 1987), and do not keep track of individual inputs into the relationship (Clark, 1984; Clark et al., 1989). In line with this research tradition, we argue that when people are confronted with friends as interaction partners both their own and their friends' outcomes matter to them. When interacting with friends, people are motivated to attend to the needs of their friends (Clark \& Mills, 1979) and, therefore, they are not only concerned with their own outcomes, but also with their friends' outcomes. When we apply this reasoning to research based on equity theory, we come to the following predictions regarding the three outcome distributions identified above.

From earlier equity research we know that people feel dissatisfied with being underpaid when interacting with unknown others (see, e.g., Adams, 1965; Austin et al., 1980; Van den Bos, Lind et al., 1997). It is neither fair nor nice to receive a relatively bad outcome, and therefore, underpaid persons will typically show negative reactions to this outcome distribution. However, as noted earlier, Clark and Mills (1979) have argued that people who interact with friends are motivated to 
attend to the needs of the other (see also Clark, 1984; Clark et al., 1987, 1989). It can thus be expected that being underpaid is less dissatisfying, when this is done relative to friends as opposed to unknown others. We, therefore, predict that underpaid people will be less dissatisfied when they are underpaid compared to friends than when they are underpaid compared to unknown others.

From earlier equity research, we also know that people feel only moderately satisfied with being overpaid when interacting with unknown others (see, e.g., Adams, 1965; Austin et al., 1980; Van den Bos, Lind et al., 1997). On the one hand, it is nice to receive a relatively good outcome, but on the other hand it is not fair to receive a better outcome than a comparable other person. However, we would like to build our line of reasoning on Clark and Mills (1979), who have argued, as noted above, that people who interact with friends are motivated to act for the needs of others (see also Clark, 1984; Clark et al., 1987, 1989). It can be expected that being overpaid is less satisfying when this is done relative to friends as opposed to unknown others. Hence, we predict that overpaid people will be less satisfied when they are overpaid compared to friends than when they are overpaid compared to unknown others.

Finally, equity research has shown that people feel satisfied with being equitably paid when interacting with unknown others (e.g., Adams, 1965; Austin et al., 1980; Van den Bos, Lind et al., 1997), as it is both fair and nice to receive an equitable outcome compared to someone who has worked equally hard (see, e.g., Van den Bos et al., 2006). Again, we base our line of reasoning on Clark and Mills (1979), who have argued that people who interact with friends are motivated to attend to the needs of others (Clark, 1984, Clark et al., 1987, 1989). One prediction, therefore, could be that people will be even more satisfied with being equitably paid when they interact with friends than when they interact with unknown others, because it could be even more satisfying when you and your friend have received equitable outcomes (cf. Clark, 1984; Clark \& Mills, 1979; Clark et al., 1987, 1989). On the other hand, it should be noted that it could also be predicted that in general people already react in such a positive way when being equitably paid in the presence of unknown others (see, e.g., Adams, 1965; Austin et al., 1980; Van den Bos, Lind et al., 1997), that the kind of relationship people have with their interaction partner may not make much of a difference, because receiving fair and equitable outcomes has such strong positive effects on evaluations of outcome satisfaction (see, e.g., Adams, 1965; Austin et al., 1980; Messick, 1993; Van den Bos, Lind et al., 1997). Since both of these predictions seem to have some merit, we assess for exploratory purposes whether relationship type will or will not moderate people's reactions to being equitably paid.

\section{Experiment 1}

In Experiment 1, participants responded to outcome distributions that were constructed following earlier research by Van den Bos (1999, Experiment 1). In line with earlier research, participants in this experiment were exposed to situations in which there is another person who is comparable to participants with respect to 
the amount of input they have provided (e.g., Austin et al., 1980; Van den Bos, Lind et al., 1997; Van den Bos, Wilke, Lind, \& Vermunt, 1998). The outcome that participants received was held constant across conditions, and we verified whether the outcome was worse than the other person's outcome (underpayment condition), better than the outcome of the other person (overpayment condition), or equal to the outcome of the other person (equal payment condition). We manipulated whether the comparable other person was either a friend or an unknown other. The latter control condition was a replication of earlier equity studies. The dependent variables assessed how satisfied participants were with the outcomes they received (see, e.g., Van den Bos, Lind et al., 1997; Van den Bos et al., 1998).

\section{Method}

\section{Participants and Design}

A mixed-gender sample of 126 students at the Free University Amsterdam participated in the experiment and was paid for their participation. ${ }^{1}$ Participants were randomly assigned to one of the conditions of the 2 (relationship type: friend versus unknown other) $\times 3$ (payment condition: equal payment versus overpayment versus underpayment) factorial design.

\section{Experimental Procedure}

Participants completed the experiment after participating in other, unrelated experiments. The experiments lasted a total of $1 \mathrm{~h}$, and participants were paid 7 Euros for their participation. On arrival at the laboratory, participants were led to separate cubicles, each of which contained an envelope and a pencil. Inside the envelopes, participants found the stimulus information and the questions that assessed the dependent variables.

Participants were asked to imagine the following situation (manipulated information in italics):

Last summer you had a job together with a friend/another student. The two of you worked together in a pair. There were a large number of such pairs in the organization where you worked. You and your friend/the other student have worked equally hard and performed equally well. Because the organization performed well last summer, it is announced on the last day of summer that a bonus of 5,000 Euros will be distributed among all employees. A certain amount of money has been allocated to you and your friend/the other student. It has to be decided how this amount of money will be distributed between you and your friend/the other student.

\footnotetext{
1 The precise gender distribution of the participants in this experiment was unknown to the experimenters. Usually we do not find gender differences in our equity studies (see e.g., Peters, Van den Bos, \& Bobocel, 2004; Peters, Van den Bos, \& Karremans, 2005; Van den Bos et al., 2006; Van den Bos \& Van Prooijen, 2001); this is an issue to which we will return in Experiment 2 (see Footnote 2).
} 
This was followed by the manipulation of outcome. Participants read the following sentences (manipulated information in italics):

A week after this employees are paid. You receive a bonus of 200 Euros. Your friend/the other student receives a bonus of 100/200/300 Euros.

After this, participants were asked questions pertaining to the dependent variable: Participants were asked how satisfied they were with the bonus they received $(1=$ very dissatisfied, $7=$ very satisfied $)$. After completing this question, participants were thoroughly debriefed and paid for their participation.

\section{Results and Discussion}

\section{Perceived Satisfaction}

As predicted, a $2 \times 3$ analysis of variance (ANOVA) on participants' outcome satisfaction showed a main effect of the outcome, $F(2,120)=26.53, p<.01$, and a significant interaction effect, $F(2,120)=4.55, p<.02$. In order to interpret these effects, we performed a least significant difference test for multiple comparisons between means ( $p<.05$; see Kirk, 1982), with the 6 cells of our design serving as the independent variable. Table 1 shows the results of this test as well as the means and standard deviations of participants' outcome satisfaction evaluations. As predicted, results showed that within the overpayment condition, participants were less satisfied with their outcome when their interaction partner was a friend than when their interaction partner was an unknown other student. The underpayment condition, unfortunately, did not show the predicted effects. When participants were being underpaid, they were equally satisfied when their interaction partner was either a friend or an unknown other. We will come back to this issue in Experiment 2 and in the General Discussion. Finally, findings revealed that in the equal payment condition, our second prediction was supported to a greater extent. That is, relationship type did not significantly moderate people's reactions to being equally paid. People reacted in such a positive way when being equitably paid, that the kind of relationship they had with their interaction partner did not make much of a

Table 1 Means and standard deviations of outcome satisfaction as a function of payment condition and interaction partner (Experiment 1)

\begin{tabular}{|c|c|c|c|c|c|c|}
\hline & \multicolumn{6}{|c|}{ Payment condition } \\
\hline & \multicolumn{2}{|c|}{ Underpayment } & \multicolumn{2}{|c|}{ Overpayment } & \multicolumn{2}{|c|}{ Equal Payment } \\
\hline & $M$ & $S D$ & $M$ & $S D$ & $M$ & $S D$ \\
\hline Unknown other & $3.7_{\mathrm{c}}$ & 1.6 & $5.6_{\mathrm{b}}$ & 1.5 & $6.0_{\mathrm{a}, \mathrm{b}}$ & 1.5 \\
\hline Friend & $4.0_{c}$ & 1.7 & $4.3_{\mathrm{c}}$ & 1.9 & $6.6_{a}$ & 0.8 \\
\hline
\end{tabular}

Note: Means are on 7-point scales, with higher values indicating higher levels of outcome satisfaction. Means with no subscripts in common differ significantly $(p<.05)$, as indicated by a least significant difference test for multiple comparisons between means (see Kirk, 1982). 
difference. We will return to this finding in Experiment 2 and in the General Discussion.

Additionally, it can be noted here that within the condition with an unknown other as interaction partner, participants were as satisfied in the equal payment condition as in the overpayment condition, and participants were more satisfied in the equal payment and overpayment conditions than in the underpayment condition (see Table 1). Usually, equity findings show that equal payment leads people to be more satisfied than overpayment. However, Van Yperen and Buunk (1991) note that this pattern of means is not always found in equity studies. These authors note that sometimes a pattern similar to ours is described in the literature and that it is demonstrated that equal payment and overpayment can show equally high satisfaction judgments. Also Hegtvedt (1990) argued that there is evidence that over-rewarded individuals are sometimes just as satisfied with their relationship as equitably rewarded individuals. We will come back to this in the General Discussion.

One might wonder whether similar results would be obtained when participants are exposed to a situation in which they actually have to complete tasks, and in which they directly experience the distribution of outcomes and the presence of an interaction partner. In Experiment 2, therefore, we wanted to replicate the findings concerning the overpayment condition in an experiment in which participants really experienced being overpaid with regard to a friend or an unknown other. Furthermore, we wanted to find support for our prediction concerning the underpayment condition and further explore the effects relationship type may have on outcome satisfaction evaluations in the equal payment condition. An additional goal of Experiment 2 was to add one item to the dependent variables, so that the reliability of our dependent variables could be assessed.

\section{Experiment 2}

Experiment 2 was constructed following the experimental paradigm developed by Van den Bos, Lind et al. (1997, Experiment 2). The participants either participated in the experiment with a friend or with someone they did not know. On the flyers that invited students to the laboratory, it was suggested that people could bring a friend along to the experiment and many of them followed this suggestion. Therefore, half of the participants interacted in the experiment with a friend they brought with them to the experiment and the other half of the participants interacted in the experiment with a person they had not met before and would not meet afterwards. Participants completed tasks together with the other participant (friend or unknown other) and learned that their own task performance was comparable to the other participant's task performance. The outcome that participants received for their performance was either equal to the outcome of the other participant (equal payment condition), better than the outcome of the other participant (overpayment condition), or worse than the outcome of the other participant (underpayment condition). The outcome that participants received was held constant, while the outcome of the other participant was varied. Outcome satisfaction was the main dependent variable. 
Method

\section{Participants and Design}

A total of 136 students (30 men and 106 women) at Utrecht University participated in the experiment and were paid for their participation. Participants were randomly assigned to one of the conditions of the 2 (relationship type: friend versus unknown other) $\times 3$ (payment condition: equal payment versus overpayment versus underpayment) factorial design. ${ }^{2}$

\section{Experimental Procedure}

Participants worked on the experimental tasks and answered the questions that constituted the dependent variables before participating in other, unrelated experiments. The experiments lasted for $30 \mathrm{~min}$, and participants were paid 4 Euros for their participation. Participants were invited to participate in a study on how people make judgments. On arrival at the laboratory, participants were led to separate cubicles, each of which contained a computer with a monitor and a keyboard. The computers were used to present the stimulus information and to measure the manipulation checks and the dependent variables.

In the first part of the instructions, participants were informed that they participated in the experiment with another person. For half of the participants, this other person was a friend with whom they arrived at the laboratory. These participants were asked to type the name and sex of their friend into the computer to make sure they understood that they were interacting with their friend. In addition, this information was used in the experiment, so that every time the interaction partner was addressed, his or her real name was used. To the other half of the participants it was communicated that they would be interacting with another participant, who was unknown to them. The experimental procedure was then outlined to the participants: After the experimental tasks were explained, participants would work on the tasks for $10 \mathrm{~min}$. Furthermore, participants were informed that, after all participants had participated, a lottery would be held among all participants. The winner of this lottery would receive 50 Euros. (After all participants had completed the experiment, the 50 Euros were randomly given to one participant; none of the participants objected to this procedure.) Participants were told that a total of 200 lottery tickets would be divided among all participants. Furthermore, participants were told that after the tasks had been completed, the experimenter would divide some lottery tickets between them and the other participant. Six practice questions were posed to ensure comprehension of the experimental procedure. If participants gave a wrong answer to a question, the correct answer was disclosed, and main characteristics of the experimental procedure were repeated.

\footnotetext{
${ }^{2}$ As expected (see Footnote 1) gender did not alter any of the results of Experiment 2, and hence was dropped from the analysis presented here. Unfortunately the number of participants was not enough to compare same-sex and mixed-sex pairs.
} 
The tasks were then explained to the participants: Participants were asked to answer questions that measured general knowledge for $10 \mathrm{~min}$. They were told that both they and the other participant had to answer the same questions. After the tasks had ended, participants were informed about the number of questions that they had answered correctly, and it was communicated to the participants that the other participant had answered an equivalent amount of questions correctly (cf. Van den Bos, Lind et al., 1997).

Participants were then told that the experimenter would divide the lottery tickets between them and the other participant. It was communicated to the participants that they received 3 lottery tickets. This was followed by the manipulation of the outcome of the other participant. In the underpayment condition, participants were informed that the other participant received 5 tickets. In the overpayment condition, participants were informed that the other participant received 1 ticket. In the equal payment condition, participants were informed that the other participant received 3 tickets.

Participants were then asked questions pertaining to the dependent variables and manipulation checks. All ratings were made on 7-point scales. Main dependent variables were participants' satisfaction judgments. Participants were asked how satisfied they were with the 3 lottery tickets they received $(1=$ very dissatisfied, $7=$ very satisfied) and how content they were with the 3 lottery tickets they received $(1=$ very discontent, $7=$ very content $)$. The satisfaction ratings were averaged to form a reliable scale of participants' outcome satisfaction $($ alpha $=.78)$.

Fairness judgments were solicited by asking questions about the fairness of the lottery tickets received. Participants were asked how fair they judged the 3 lottery tickets they received $(1=$ very unfair, $7=$ very fair $)$ and how just they judged the 3 lottery tickets they received $(1=$ very unjust, $7=$ very just $)$. These items were averaged to form a reliable scale of participants' outcome fairness judgments $($ alpha $=.94)$.

As checks on the manipulation of the three outcome conditions, participants were asked two questions for each condition. As a check on the manipulation of overpayment, participants were asked to what extent they agreed with the statement that they received more lottery tickets than the other participant $(1=$ strongly disagree, $7=$ strongly agree $)$ and to what extent they agreed with the statement that the other participant received fewer lottery tickets than they received $(1=$ strongly disagree, $7=$ strongly agree). Answers to these two items were averaged to form a reliable check of the overpayment condition (alpha $=.98$ ). As a check on the manipulation of equal payment, participants were asked to what extent they agreed with the statement that they received an equal number of lottery tickets as the other participant $(1=$ strongly disagree, $7=$ strongly agree $)$ and to what extent they agreed with the statement that the other participant received an equal number of lottery tickets as they received $(1=$ strongly disagree, $7=$ strongly agree $)$. Answers to these two items were averaged to form a reliable check of the equal payment condition (alpha $=.98$ ). As a check on the manipulation of underpayment, participants were asked to what extent they agreed with the statement that they received fewer lottery tickets than the other participant $(1=$ strongly disagree, 
7 = strongly agree $)$ and to what extent they agreed with the statement that the other participant received more lottery tickets than they received $(1=$ strongly disagree, 7 = strongly agree). Answers to these two items were averaged to form a reliable check of the underpayment condition (alpha $=.96$ ).

As a check on the manipulation of relationship type (friend versus unknown other), participants were asked how close they felt to the other participant. Participants were asked to what extent they felt committed to the other participant $(1=$ not at all, $7=$ very much $)$, to what extent they felt connected with the other participant $(1=$ not at all, $7=$ very $m u c h)$, how close their relationship with the other participant was $(1=$ not at all close, $7=$ very close $)$, and participants were asked to respond to the Inclusion of Other in the Self (IOS) scale (Aron et al., 1991). The latter scale is a single-item, pictorial measure of closeness (see Aron et al., 1991). Because all four items were highly correlated with each other ( $r$ 's $>.70)$, answers to these four items were averaged to form a reliable check of the relationship orientation manipulation (alpha $=.93$ ).

In order to assess whether participants thought of the other participant as a comparable person with respect to task performance, they were asked to what extent the other participant worked equally hard in reference to the participants themselves ( $1=$ much worse, $4=$ equally hard, $7=$ much better $)$, to what extent the other participant did his or her best in reference to the participants themselves $(1=$ much worse, $4=$ equally, $7=$ much better), and to what extent the other participant was good in performing the task relative to the participants themselves $(1=$ much worse, $4=$ equally good, $7=$ much better .

\section{Results and Discussion}

\section{Outcome Manipulation Check}

A $2 \times 3$ multivariate analysis of variance (MANOVA) on the three manipulation checks of outcome yielded only a main effect of outcome at both the multivariate level and the univariate levels, multivariate $F(6,256)=1336.44, p<.01$; for the overpayment check, $F(2,130)=2131.26, p<.01$; for the equal payment check, $F(2,130)=1351.88, p<.01$; for the underpayment check, $F(2,130)=929.70$, $p<.01$. In order to interpret these effects, we performed for each manipulation check a least significant difference test for multiple comparisons between means ( $p<.05$; see Kirk, 1982), with the three conditions of the outcome manipulation serving as the independent variable. This showed that participants in the overpayment condition agreed more with the statements that they received an outcome that was better than the other participant's outcome $(M=6.8, S D=.6)$ than participants in the equal payment $(M=1.2, S D=.4)$ and underpayment conditions $(M=1.3, S D=.8)$ and that no other differences between conditions were significant. Participants in the equal payment condition agreed more with the statements that their outcome was equal to the outcome of the other participant $(M=6.6, S D=1.0)$ than participants in the overpayment $(M=1.2, S D=.5)$ and underpayment conditions $(M=1.2, S D=.7)$, and no other differences between 
conditions were significant. Participants in the underpayment condition agreed more with the statements that their outcome was worse than the other participant's outcome $(M=6.9, S D=.3)$ than participants in the equal payment $(M=1.2$, $S D=.5)$ and overpayment conditions $(M=1.1, S D=.3)$, and no other differences between conditions were significant. These findings suggest that the outcome manipulation was successfully operationalized.

\section{Relationship Type Check}

The answers that participants gave to the questions assessing whether participants felt close to their interaction partner were subjected to a $2 \times 3$ ANOVA. This ANOVA yielded only a main effect of relationship type (unknown other or friend), $F(1,130)=201.92, p<.01$. Inspection of the means indicated that participants felt closer to the other participant when the other was a friend $(M=4.9, S D=1.1)$ than when the other was unknown to them $(M=2.2, S D=1.0)$.

\section{Additional Measures}

The answers that participants gave to the questions that assessed whether participants perceived the interaction partner to be a comparable person with respect to task performance were subjected to a $2 \times 3$ MANOVA. This MANOVA did not yield significant results at either the multivariate level or the univariate levels. Inspection of the means indicated that participants perceived the other person to be working equally hard $(M=4.0)$, to be doing his or her best $(M=4.0)$, and to be equally good in performing the tasks $(M=4.0)$. Thus, these findings showed that participants' interaction partner was seen as a comparable person.

\section{Fairness Judgments}

Participants' outcome fairness judgments yielded only a main effect of outcome, $F(2,130)=77.58, p<.01$. As expected, a least significant difference test $(p<.05)$, with the three conditions of the outcome manipulation serving as the independent variable, revealed that participants in the equal payment condition judged their outcomes to be more fair $(M=5.6, S D=.9)$ than those in the overpayment $(M=3.1, S D=1.2)$ and underpayment conditions $(M=3.2$, $S D=1.2$ ), and that no other differences between conditions were significant. These findings are in accordance with previous equity studies (e.g., Van den Bos, Lind et al., 1997; Van den Bos et al., 1998), which showed that equal outcomes were judged to be fair and unequal outcomes to be unfair, and hence yield additional evidence that the outcome manipulation was perceived as intended.

\section{Perceived Satisfaction}

Main dependent variables were participants' perceptions of outcome satisfaction. In order to analyze the data, we first conducted a $2 \times 3$ ANOVA. As predicted, this 
ANOVA showed a significant main effect of outcome, $F(2,130)=16.04, p<.01$, and a significant interaction effect, $F(2,130)=4.46, p<.02$. In order to interpret these effects we performed a least significant difference test for multiple comparisons between means $(p<.05)$, with the 6 cells of our design serving as the independent variable. Table 2 shows the results of this test as well as the means and standard deviations of the outcome satisfaction scale. As predicted, findings revealed that participants were more satisfied with their overpayment when the other participant was an unknown other rather than a friend. Furthermore, in accordance with our predictions, findings revealed that participants were more satisfied with their underpayment when the other participant was a friend rather than an unknown other. Finally, regarding the equal payment condition, relationship type did not significantly moderate people's reactions to being equally paid. People reacted in such a positive way when being equitably paid that the kind of relationship they had with their interaction partner did not make much of a difference. The results of Experiment 2 supports our second prediction regarding the equal payment condition to a greater extent. We will come back to this issue in the General Discussion.

In order to conclude, in Experiment 2, we replicated the findings of Experiment 1 concerning our prediction regarding the overpayment condition in a real experiment. Moreover, we found support for our prediction regarding the underpayment condition. And finally, our second expectation regarding people's reactions in the equal payment condition was again supported. Thus, when participants really experience being equitably or inequitably paid, our hypotheses are supported. Furthermore, in Experiment 2, we again found that participants in the control (unknown other) condition were equally satisfied with being overpaid as with being equally paid (cf. Buunk \& Van Yperen, 1989; Hegtvedt, 1990). We will provide an explanation for this finding in the General Discussion.

\section{General Discussion}

The current article has examined people's reactions to being equitably and inequitably paid when they interact with friends versus unknown others. Two experiments generally provide evidence in support of our hypotheses. As predicted,

Table 2 Means and standard deviations of outcome satisfaction as a function of payment condition and interaction partner (Experiment 2)

\begin{tabular}{|c|c|c|c|c|c|c|}
\hline & \multicolumn{6}{|c|}{ Payment condition } \\
\hline & \multicolumn{2}{|c|}{ Underpayment } & \multicolumn{2}{|c|}{ Overpayment } & \multicolumn{2}{|c|}{ Equal Payment } \\
\hline & $M$ & $S D$ & $M$ & $S D$ & $M$ & $S D$ \\
\hline Unknown other & $3.5_{\mathrm{d}}$ & 1.3 & $5.3_{\mathrm{a}}$ & 0.8 & $5.4_{\mathrm{a}}$ & 1.1 \\
\hline Friend & $4.2_{\mathrm{c}}$ & 1.1 & $4.5_{\mathrm{b}, \mathrm{c}}$ & 1.6 & $5.1_{\mathrm{a}, \mathrm{b}}$ & 1.1 \\
\hline
\end{tabular}

Note: Means are on 7-point scales, with higher values indicating higher levels of outcome satisfaction. Means with no subscripts in common differ significantly $(p<.05)$, as indicated by a least significant difference test for multiple comparisons between means (see Kirk, 1982). 
relationship type affects people's satisfaction judgments when they are being overpaid. The results of both experiments show that people are less satisfied with being overpaid when their interaction partners are friends rather than when their interaction partners are unknown others. Furthermore, as predicted, relationship type also affects people's satisfaction judgments when they are being underpaid. That is, the results of Experiment 2 show that people are more satisfied with being underpaid when their interaction partners are friends rather than when their interaction partners are unknown others. Finally, we examined the effects of relationship type on satisfaction judgments when being equitably paid for exploratory purposes. Both experiments demonstrated that relationship type did not have statistically significant effects when people were equitably paid, suggesting that relationship type did not moderate satisfaction with equitable outcomes and thus providing support for our second hypothesis. Apparently, in general people already react in such a positive way when being equitably paid (Adams, 1965; Austin et al., 1980; Messick, 1993; Van den Bos, Lind et al., 1997), that the kind of relationship they have with their interaction partner does not make much of a difference. Participants are highly satisfied with being equitably paid, both when their interaction partners are friends as well as unknown others.

Thus, the results of our two experiments demonstrate that relationship type affects people's reactions to being inequitably paid. Although equity theory has stressed the importance of the amount of inputs that are provided and outcomes that are received by both partners in an interaction (Adams, 1965; Walster et al., 1973, 1978), we would like to stress that characteristics of the relationship itself have an important influence on people's reactions to inequitable outcomes. An important implication of the current findings is that how people respond to injustice is more susceptible to the characteristics of the situation than one might think (for a related line of reasoning, see Mikula \& Wenzel, 2000). With the studies presented here, we have demonstrated that interacting with friends can be a crucial variable in people's reactions to being overpaid and being underpaid. When interacting with friends, people are motivated to attend to the needs of their friends and they are not only concerned with their own outcomes, but also with their friends' outcomes.

The results of the current article fit in a research tradition that examines equity in close relationships. For instance, although Wicker and Bushweiler (1970) focused on experiences of pleasantness with experiments, and not on satisfaction with equitable and inequitable outcome distributions, their work is interesting for the current purposes because they suggest that the degree of closeness between respondents and their interaction partners may be an important determinant of experienced pleasantness in social interactions. Other studies that resemble the current research to a greater extent were conducted by Van Yperen and Buunk (1994; see also Buunk \& Van Yperen, 1991; Van Yperen \& Buunk, 1990, 1991). These authors also examined equity in close relationships, although they mainly applied equity research to marital relationships. Van Yperen and Buunk (1994) have argued that when someone feels overbenefitted in his or her marriage, this person feels moderately satisfied with his or her marriage and that when someone feels underbenefitted in his or her marriage, this person feels dissatisfied with his or her marriage. We would like to note, however, that this research was cross-sectional. 
Despite their interesting correlational findings, no conclusions can be drawn regarding the causal relation between relationship type and satisfaction with outcomes. With the experiments conducted in the present article, we have extended the intriguing line of reasoning by Van Yperen and Buunk, and by manipulating type of relationship we have created a context to confidently study causal relations.

Furthermore, Van Yperen and Buunk (1994) did not measure people's direct reactions to being inequitably paid, but they measured people's satisfaction with a marriage in which they were overbenefitted or underbenefitted. Being overbenefitted or underbenefitted in a marital relationship implies that the relationship itself is inequitable. This has more extensive consequences for a relationship than being in a friendship relation in which one of the two persons accidentally receives more credit or better outcomes. However, as the results of the current article show, even when the other person in a payment situation is not a spouse but merely a friend, which can be seen as a weaker manipulation of a communal relationship, the effects of satisfaction judgments with inequitable outcomes can still be found. The current research, therefore, provided support for the strength and robustness of equity findings obtained in close relationships. Our experiments have extended the research conducted in a research tradition of equity in close relationships and have hopefully made a unique contribution to the integration of the literature on equity evaluations and the literature on communal and exchange relationships.

We would also like to discuss the fact that our hypothesis regarding the overpayment condition was supported in both Experiments 1 and 2, whereas our hypothesis regarding the underpayment condition yielded only supportive evidence in Experiment 2. Experiment 2 used strong manipulations in which people actually received an outcome relative to another participant that was present at the same time, whereas Experiment 1 employed a scenario methodology with arguably weaker manipulations. This suggests that our hypothesis regarding the underpayment condition is more likely to be supported when strong relationship manipulations are used. Furthermore, this suggests that the hypothesis regarding the overpayment condition could more easily be supported than the hypothesis regarding the underpayment condition. A possible explanation for this finding is provided by Loewenstein et al. (1989). These authors argued that people's attitude toward overpayment could be affected more easily and to a greater extent than people's attitudes towards underpayment, because of the greater ambiguity in people's reactions to being overpaid (see also Peters, Van den Bos, \& Bobocel, 2004). This might be a reason why the hypothesis regarding underpayment yielded somewhat weaker support and probably needs stronger manipulations to obtain the effects predicted by this hypothesis. The most important thing, in our opinion, seems to be the conclusion that both hypotheses are supported when a strong enough manipulation is used.

We would like to take the opportunity here to go somewhat deeper into the results in the equitable payment condition. That is, we would like to note here that, although our second prediction was supported twice and relationship type did not moderate the effects of people's reactions to being equitably paid, the findings of Experiment 1 suggest that people do show a tendency to be somewhat more satisfied with equitable outcomes when interacting with friends, as opposed to unknown 
others, as can be seen in Table 1. In fact, the non-significance of this effect could be caused by a ceiling effect. Please note, however, that findings of Experiment 2 clearly do not show this tendency, and, even more importantly, there is no indication of a ceiling effect there (see Table 2). A possible explanation for the findings indicating that relationship type did not significantly moderate the effects of people's reactions to being equitably paid in both our experiments will be provided below.

That is, we would like to integrate the present findings with a large and diverse body of research suggesting that negative information influences people's evaluations more strongly than positive information (see, e.g., Ito, Larsen, Smith, \& Cacioppo, 1998; Skowronski \& Carlston, 1989). In general, there has been a tendency for negative events to have more impact than positive events (Taylor, 1991). In other words, many researchers have demonstrated a negativity bias. In the justice literature, this has led to the idea that unjust events affect lay people's cognitions and reactions more strongly than just events (Brockner \& Wiesenfeld, 1996; Van den Bos, Vermunt, \& Wilke, 1997), suggesting that injustice plays a more prominent role and that it might be better to talk about the psychology of injustice as opposed to justice (Folger, 1984; Folger \& Cropanzano, 1998; Van den Bos \& Van Prooijen, 2001). In other words, many effects reported in justice research are based on effects of injustice and not so much on effects of justice. Extending this reasoning, it might also be the case that our prediction that people are concerned with their friends' outcomes is more relevant in inequitable situations (i.e., being under- and overpaid) than in equitable situations. This would suggest that an explanation for the lack of effect of relationship type in our equitable payment conditions might be that our predicted effects are especially relevant for the two inequitable outcome distributions, but only to a lesser extent for equitable outcome distributions (for related lines of reasoning, see also Folger, 1984; Folger \& Cropanzano, 1998; Van den Bos \& Van Prooijen, 2001).

The discussion of the present findings can, in our opinion, not be complete without discussing research instigated by Deutsch (1975), who makes a distinction between different justice principles. Deutsch noted that equity is only one of the many possible principles of distributive justice, and that people could also use, for example, the principles of equality or need (see also, Lamm \& Schwinger, 1980; Leventhal, 1976). Furthermore, Deutsch argued that the principles of equality and need are more important justice principles in close relationships than the principle of equity. We would like to note, however, that these different principles of justice are used in proactive types of justice research, whereas the research we conducted is more reactive in nature (see Greenberg, 1987). That is, in our experiments people have to react to outcome evaluations, instead of allocating resources themselves. Although one could argue that the justice principles used for (proactively) distributing resources may also refer to (reactively) responding to outcome distributions, we would like to emphasize that, to our knowledge, this has not yet been demonstrated. Future research should, therefore, address whether these different justice principles could also be applied to more reactive types of justice (cf. Greenberg, 1987), like the ones we investigated in the current article. More importantly, in our research there was no distinction between principles of equity 
and principles of equality, because people's inputs did not differ. When only inputs or only outcomes are examined, the issue of equity turns into the issue of equality (Van Yperen \& Buunk, 1994). Therefore, on the basis of these data it is difficult to tell which justice principle causes the effects. Future research might disentangle the effects of different justice principles on evaluations of outcome distributions.

As mentioned earlier, one could easily relate this research to the literature concerning categorization and intergroup relations. Elaborating on these concepts in detail is beyond the scope of the current article. However, we would like to suggest that the effect we describe in this article is strongly linked to ideas of ingroup favoritism (Brewer, 1979; Spears, Jetten, \& Doosje, 2001), social dominance orientation (Sidanius, Levin, Frederico, \& Pratto, 2001), social identity (Ellemers, 2001; Spears et al., 2001), group justification (Jost, Burgess, \& Mosso, 2001), categorization (Tajfel \& Turner, 1979; Tajfel \& Wilkes, 1963), and ego-defense or ego-justification (Major \& Schmader, 2001).

With the experiments presented here, we have focused on the question of when justice is important to people. We have explored the social conditions under which the importance of justice may change in social interactions. More specifically, we have examined how different types of relationships affect evaluations of just and unjust situations. We have provided support for the idea that being in a communal relationship, as opposed to being in an exchange relationship, makes people react differently to inequitable outcome distributions because they are motivated to attend to the needs of the other. Therefore, justice is especially important to people when they are in communal relationships.

Acknowledgments The work in this article was supported by a grant from the Netherlands Organization for Scientific Research (NWO, 410-21-005-P). We would like to thank Johan C. Karremans for his comments on earlier drafts of this article; Nickie van der Wulp for her assistance in collecting the data of Experiment 1; and Sarah Alex, Eveline Hadewegg Scheffer, and Marieke Ossendrijver for their assistance in collecting the data of Experiment 2.

\section{References}

Adams, J. S. (1965). Inequity in social exchange. In L. Berkowitz (Ed.), Advances in experimental social psychology, (Vol. 2, pp. 267-299). New York: Academic Press.

Aron, A., \& Aron, E. N. (1986). Love as the expansion of self: Understanding attraction and satisfaction. New York: Hemisphere.

Aron, A., Aron, E. N., Tudor, M., \& Nelson, G. (1991). Close relationships as including other in self. Journal of Personality and Social Psychology, 60, 241-253.

Austin, W., McGinn, N. C., \& Susmilch, C. (1980). Internal standards revisited: Effects of social comparisons and expectancies on judgments of fairness and satisfaction. Journal of Experimental Social Psychology, 16, 426-441.

Austin, W., \& Walster, E. (1974). Reactions to confirmations and disconformations of expectancies of equity and inequity. Journal of Personality and Social Psychology, 30, 208-216.

Boles, T. L., \& Messick, D. M. (1995). A reverse outcome bias: The influence of multiple reference points on the evaluation of outcomes and decisions. Organizational Behavior and Human Decision Processes, 61, 262-275.

Brewer, M. (1979). In-group bias in the minimal intergroup situation: A cognitive motivational analysis. Psychological Bulletin, 86, 307-324.

Brockner, J., \& Wiesenfeld, B. M. (1996). An integrative framework for explaining reactions to decisions: Interactive effects of outcomes and procedures. Psychological Bulletin, 120, 189-208. 
Buunk, B. P., \& Van Yperen, N. W. (1989). Social comparison, equality, and relationship satisfaction: Gender differences over a ten-year period. Social Justice Research 3, 157-180.

Buunk, B. P., \& Van Yperen, N. W. (1991). Referential comparisons, relational comparisons, and exchange orientation: Their relation to marital satisfaction. Personality and Social Psychology Bulletin, 17, 709-717.

Clark, M. S. (1984). Record keeping in two types of relationships. Journal of Personality and Social Psychology, 47, 549-557.

Clark, M. S., \& Mills, J. (1979). Interpersonal attraction in exchange and communal relationships. Journal of Personality and Social Psychology, 37, 12-24.

Clark, M. S., \& Mills, J. (1993). The difference between communal and exchange relationships: What it is and is not. Personality and Social Psychology Bulletin, 19, 684-691.

Clark, M. S., Mills, J., \& Corcoran, D. M. (1989). Keeping track of needs and inputs of friends and strangers. Personality and Social Psychology Bulletin, 15, 533-542.

Clark, M. S., Ouellette, R., Powell, M. C., \& Milberg, S. (1987). Recipient's mood, relationship type, and helping. Journal of Personality and Social Psychology, 53, 94-103.

Deutsch, M. (1975). Equity, equality, or need? What determines which value will be used as the basis of distributive justice? The Journal of Social Issues 31, 137-149.

Ellemers, N. (2001). Individual upward mobility and the perceived legitimacy of intergroup relations. In J. T. Jost \& B. Major (Eds.), The psychology of legitimacy. Cambridge: Cambridge University Press.

Folger, R. (1984). The sense of injustice: Social psychological perspectives. New York: Plenum Press.

Folger, R., \& Cropanzano, R. (1998). Organizational justice and human resource management. Thousand Oaks: Sage.

Greenberg, J. (1987). A taxonomy of organizational justice theories. Academy of Management Review, 12, 9-22.

Hatfield, E. (1982). Passionate love, compassionate love, and intimacy. In M. Fisher \& G. Stricker (Eds.), Intimacy (pp. 267-292). New York: Plenum Press.

Hegtvedt, K. A. (1990). The effects of relationship structure on emotional responses to inequity. Social Psychology Quarterly, 53, 214-228.

Hobbes, T. (1651/1904). Leviathan, or matter, forme and power of a commonwealth ecclesiastical and civil. Cambridge: Cambridge University Press.

Ito, T. A., Larsen, J. T., Smith, N. K., \& Cacioppo, J. T. (1998). Negative information weighs more heavily on the brain: The negativity bias in evaluative categorizations. Journal of Personality and Social Psychology, 75, 887-900.

Jost, J. T., Burgess, D., \& Mosso, C. O. (2001). Conflicts among legitimation among self, group, and system: The integrative potential of system justification theory. In J. T. Jost \& B. Major (Eds.), The psychology of legitimacy. Cambridge: Cambridge University Press.

Kelley, H. H., \& Thibaut, J. W. (1978). Interpersonal relations: A theory of interdependence. New York: John Wiley \& Sons.

Kirk, R. E. (1982). Experimental design: Procedures for the behavioral sciences (2nd ed.). Belmont: Brooks/Cole.

Komorita, S. S., \& Chertkoff, J. M. (1973). A bargaining theory of coalition formation. Psychological Review, 80, 149-162.

Lamm, H., \& Schwinger, T. (1980). Norms concerning distributive justice: Are needs taken into consideration in allocation decisions? Social Psychology Quarterly, 43, 425-429.

Lerner, M. J. (1980). The belief in a just world. New York: Plenum Press.

Lerner M. J. (1981). The justice motive in human relations: Some thoughts on what we know and need to know about justice. In M. J. Lerner \& S. C. Lerner (Eds.), The justice motive in social behavior adapting to times of scarcity and change, (pp. 47-70). New York: Plenum Press.

Leventhal G. S. (1976). The distribution of rewards and resources in groups and organizations. In L. Berkowitz \& E. Walster (Eds.), Advances in experimental social psychology: Equity theory, toward a general theory of social interaction, (Vol. 9, pp. 91-131). New York: Academic Press.

Loewenstein G. F., Thompson, L., \& Bazerman, M. H. (1989). Social utility and decision making in interpersonal contexts. Journal of Personality and Social Psychology, 57, 426-441.

Major, B., \& Schmader, T. (2001). Legitimacy and the construal of social disadvantage. In J. T. Jost \& B. Major (Eds.), The psychology of legitimacy. Cambridge: Cambridge University Press.

McDonald, G. W. (1981). Structural exchange and marital interaction. Journal of Marriage and the Family, 43, 825-839. 
Messick, D. M. (1993). Equality as a decision heuristic. In B. A. Mellers \& J. Baron (Eds.), Psychological perspectives on justice: Theory and applications, (pp. 11-31). Cambridge: Cambridge University Press.

Messick, D. M., \& Sentis, K. (1985). Estimating social and nonsocial utility functions from ordinal data. European Journal of Social Psychology, 15, 389-399.

Mikula, G., \& Wenzel, M. (2000). Justice and social conflict. International Journal of Psychology, 35, $126-135$.

Mills J. \& Clark M. S. (1982). Communal and exchange relationships. In L. Wheeler (Ed), Review of personality and social psychology, (Vol. 3, pp. 121-144). Beverly Hills: Sage.

Montada, L. (2002). Doing justice to the justice motive. In M. Ross \& D. T. Miller (Eds.), The justice motive in everyday life, (pp. 41-62). New York: Cambridge University Press.

Peters, S. L., Van den Bos, K., \& Bobocel, D. R. (2004). The moral superiority effect: Self versus other differences in satisfaction with being overpaid. Social Justice Research, 17, 257-273.

Peters, S. L., Van den Bos, K., \& Karremans, J. C. (2005). On the psychology of the advantaged: How people react to being overpaid. Manuscript submitted for publication.

Schwartz, B. (1986). The battle for human nature. New York: Norton.

Sidanius, J., Levin, S., Frederico, C. M., \& Pratto, F. (2001). Legitimizing ideologies: The social dominance approach. In J. T. Jost \& B. Major (Eds.), The psychology of legitimacy. Cambridge: Cambridge University Press.

Skowronski, J. J., \& Carlston, D. E. (1989). Negativity and extremity biases in impression formation: A review of explanations. Psychological Bulletin, 105, 131-142.

Spears, R., Jetten, J., \& Doosje, B. (2001). The (il)legitimacy of ingroup bias: From social reality to social resistance. In J. T. Jost \& B. Major (Eds.), The psychology of legitimacy. Cambridge: Cambridge University Press.

Tajfel, H., \& Turner, J. C. (1979). An integrative theory of intergroup conflict. In W. G. Austin \& S. Worchel (Eds.), The social psychology of intergroup relations, (pp. 33-47). CA: Brooks/Cole, Monterey.

Tajfel, H., \& Wilkes, A. L. (1963). Classification and quantitative judgment. British Journal of Psychology, 54, 101-114.

Taylor, S. E. (1991). Asymmetrical effects of positive and negative events: The mobilizationminimization hypothesis. Psychological Bulletin, 110, 67-85.

Tyler, T. R., \& Smith, H. J. (1998). Social justice and social movements. In D. T. Gilbert \& S. T. Fiske (Eds.), The handbook of social psychology, (Vol. 2, 4th edn., pp. 595-629). New York: McGrawHill.

Van den Bos, K. (1999). What are we talking about when we talk about no-voice procedures? On the psychology of the fair outcome effect. Journal of Experimental Social Psychology, 35, 560-577.

Van den Bos, K., Lind, E. A., Vermunt, R., \& Wilke, H. A. M. (1997). How do I judge my outcome when I do not know the outcome of others? The psychology of the fair process effect. Journal of Personality and Social Psychology, 72, 1034-1046.

Van den Bos, K., Peters, S. L., Bobocel, D. R., \& Ybema, J. F. (2006). On preferences and doing the right thing: Satisfaction with advantageous inequity when cognitive processing is limited. Journal of Experimental Social Psychology, 42, 273-289.

Van den Bos, K., \& Van Prooijen, J. W. (2001). Referent cognitions theory: The role of closeness of reference points in the psychology of voice. Journal of Personality and Social Psychology, 81, 616626.

Van den Bos, K., Vermunt, R., \& Wilke, H. A. M. (1997). Procedural and distributive justice: What is fair depends more on what comes first than on what comes next. Journal of Personality and Social Psychology, 72, 95-104.

Van den Bos, K., Wilke, H. A. M., Lind E. A., \& Vermunt, R. (1998). Evaluating outcomes by means of the fair process effect: Evidence for different processes in fairness and satisfaction judgments. Journal of Personality and Social Psychology, 74, 1493-1503.

Van Yperen, N., \& Buunk, B. P. (1990). A longitudinal study of equity and satisfaction in intimate relationships. European Journal of Social Psychology, 20, 287-309.

Van Yperen, N., \& Buunk, B. P. (1991). Equity theory and exchange and communal orientation from a cross-national perspective. The journal of Social Psychology, 131, 5-20.

Van Yperen, N. W., \& Buunk, B. P. (1994). Social comparison and social exchange in marital relationships. In M. J. Lerner \& G. Mikula (Eds.), Entitlement and the affectional bond: Justice in close relationships, (pp. 89-115). New York: Plenum Press. 
Walster, E., Berscheid, E., \& Walster, G. W. (1973). New directions in equity research. Journal of Personality and Social Psychology, 25, 151-176.

Walster, E., Walster, G. W., \& Berscheid, E. (1978). Equity: Theory and research. Boston: Allyn \& Bacon.

Wicker, A. W., \& Bushweiler, G. (1970). Perceived fairness \& pleasantness of social exchange situations: Two factorial studies of inequity. Journal of Personality and Social Psychology, 15, 63-75. 